\title{
Amphibian chytrid fungus Batrachochytrium dendrobatidis in Cusuco National Park, Honduras
}

\author{
Jonathan E. Kolby ${ }^{1,2,5, *}$, Gretchen E. Padgett-Flohr ${ }^{3}$, Richard Field ${ }^{1,4}$ \\ ${ }^{1}$ Operation Wallacea, Hope House, Old Bolingbroke, Lincolnshire PE23 4EX, UK \\ ${ }^{2}$ The Conservation Agency, 6 Swinburne St., Jamestown, Rhode Island 02835, USA \\ ${ }^{3}$ Department of Zoology, Southern Illinois University-Carbondale, Carbondale, Illinois 62901, USA \\ ${ }^{4}$ Department of Geography, University of Nottingham, University Park, Nottingham NG7 2RD, UK \\ ${ }^{5}$ Present address: 1671 Edmund Terrace, Union, New Jersey 07083, USA
}

\begin{abstract}
Amphibian population declines in Honduras have long been attributed to habitat degradation and pollution, but an increasing number of declines are now being observed from within the boundaries of national parks in pristine montane environments. The amphibian chytrid fungus Batrachochytrium dendrobatidis has been implicated in these declines and was recently documented in Honduras from samples collected in Pico Bonito National Park in 2003. This report now confirms Cusuco National Park, a protected cloud forest reserve with reported amphibian declines, to be the second known site of infection for Honduras. B. dendrobatidis infection was detected in 5 amphibian species: Craugastor rostralis, Duellmanohyla soralia, Lithobates maculata, Plectrohyla dasypus, and Ptychohyla hypomykter. D. soralia, P. dasypus, and P. hypomykter are listed as critically endangered in the IUCN Red List of Threatened Species and have severely fragmented or restricted distributions. Further investigations are necessary to determine whether observed infection levels indicate an active $B$. dendrobatidis epizootic with the potential to cause further population declines and extinction.
\end{abstract}

KEY WORDS: Batrachochytrium dendrobatidis · Amphibian chytrid fungus $\cdot$ Honduras $\cdot$ Amphibian declines $\cdot$ Endangered species

\section{INTRODUCTION}

The amphibian chytrid fungus Batrachochytrium dendrobatidis is a rapidly emerging amphibian pathogen that is linked to global declines in amphibian populations (Longcore et al. 1999, Stuart et al. 2004, Weldon et al. 2004, Di Rosa et al. 2007, Skerratt et al. 2007). This organism is a member of an ancient group of fungi, the phylum Chytridiomycota, and is the only species known to be pathogenic to vertebrates. B. dendrobatidis infects the keratinized epithelial cells of amphibians and is responsible for a potentially lethal disease, amphibian chytridiomycosis. Although both larval and adult amphibians are susceptible to infection, mortality usually occurs post-metamorphosis. Infection is limited to the keratinized oral structures in larvae, whereas the amphibian epidermis becomes susceptible following metamorphosis (Berger et al. 1999). B. dendrobatidis is pandemic in its current distribution and is currently the only wildlife pathogen known to be capable of acting as both a proximate and ultimate cause for extinction (Schloegel et al. 2006). The scope of amphibian biodiversity believed to be threatened by this emerging disease is alarming and global in impact.

In Mesoamerica, infected amphibians have been recorded from Mexico (Lips et al. 2004), Guatemala (Mendelson et al. 2004), El Salvador (Felger et al. 2007), Honduras (Puschendorf et al. 2006), Costa Rica (Lips et al. 2003), and Panama (Lips 1999). High-altitude sites are most heavily affected by this pathogen, as the growth and reproductive success of Batrachochytrium dendrobatidis appears to be temperature 
dependent, thriving at $23^{\circ} \mathrm{C}$ but declining as temperatures approach $29^{\circ} \mathrm{C}$ (Longcore et al. 1999, Berger et al. 2004). Unfortunately, regions favorable to $B$. dendrobatidis in Mesoamerica also overlap with hotspots of amphibian biodiversity. This is especially true in Honduras, where most of the land above $900 \mathrm{~m}$ contains the majority of the country's remaining cloud forests. Nearly half of the 41 endemic Honduran amphibian species are reported to have declining populations or have already disappeared (Wilson \& McCranie 2004a). Historically, pressure has come from anthropogenic sources inlcuding habitat destruction, pollution, and resource exploitation; however, it is now becoming increasingly common to find declines that cannot be directly linked to such factors. Enigmatic declines have now occurred within the boundaries of Honduran national parks and may be indicative of widespread $B$. dendrobatidis epizootics (Wilson \& McCranie 2004b, Puschendorf et al. 2006). Cusuco National Park is one such example, where inexplicable declines have been reported in 3 critically endangered species: Plectrohyla dasypus, Ptychohyla hypomykter, and Duellmanohyla soralia (IUCN 2007). We hypothesized that $B$. dendrobatidis is prevalent within Cusuco National Park and that these critically endangered species are highly susceptible to infection. To test these hypotheses, we performed the first field survey in Honduras designed to detect $B$. dendrobatidis on live wild amphibians.

\section{MATERIALS AND METHODS}

Study site. This investigation was conducted in Cusuco National Park, located within the Sierra de Omoa, part of the Merendón mountain range in northwestern Honduras. The park encompasses an area of approximately $234 \mathrm{~km}^{2}$ and ranges in elevation from $700 \mathrm{~m}$ to 2242 m. Cusuco National Park is classified as a 'cloud forest' and is primarily composed of lower montane wet forest. The park receives nearly $3000 \mathrm{~mm}$ of rainfall annually and experiences monthly average temperatures ranging from $12.9^{\circ} \mathrm{C}$ to $23.1^{\circ} \mathrm{C}$ (Wilson \& McCranie 2004a). Both primary and secondary forests are present within Cusuco National Park, the distribution of which roughly overlaps with the partitioning of an inner core zone and an outer buffer zone. Delineation between the 2 zones has been subject to recent revisions, but was originally intended to consider only land above $1800 \mathrm{~m}$ as the core zone. In 2003, Operation Wallacea, a British conservation organization, began conducting annual biodiversity surveys within Cusuco National Park. Current inventories document 93 amphibian and reptile species within the park, but it is possible that the actual number is even higher due to the cryptic nature of some amphibian genera (i.e. Craugastor, Oedipina; Field \& Long 2007).

Batrachochytrium dendrobatidis sampling. Between 27 June and 21 August 2007, 257 amphibians of 16 species were opportunistically sampled for B. dendrobatidis infection in Cusuco National Park, using primarily non-lethal swabbing techniques. Sample collection concentrated around 5 main study sites (Santo Tomas, Cortecito, Cantilles, Base Camp, and Buenos Aires), which span the park diagonally from northwest to southeast (Fig. 1). Samples were collected while performing herpetological species surveys for Operation Wallacea along pre-defined transects stemming from each of these 5 sites. Adult, juvenile, and larval amphibians were sampled concurrently. Tadpoles were collected by dip-netting during daylight hours, while metamorphs, subadults, and adults were primarily collected by hand at night. To avoid cross contamination, a fresh pair of disposable Nitrile ${ }^{\circledR}$ gloves was worn each time a new amphibian was handled. In addition, dip nets were sterilized with bleach and thoroughly rinsed before moving to new sampling sites.

Amphibians were swabbed for Batrachochytrium dendrobatidis infection using protocols established by Hyatt et al. (2007), with the exception that $70 \% \mathrm{EtOH}$

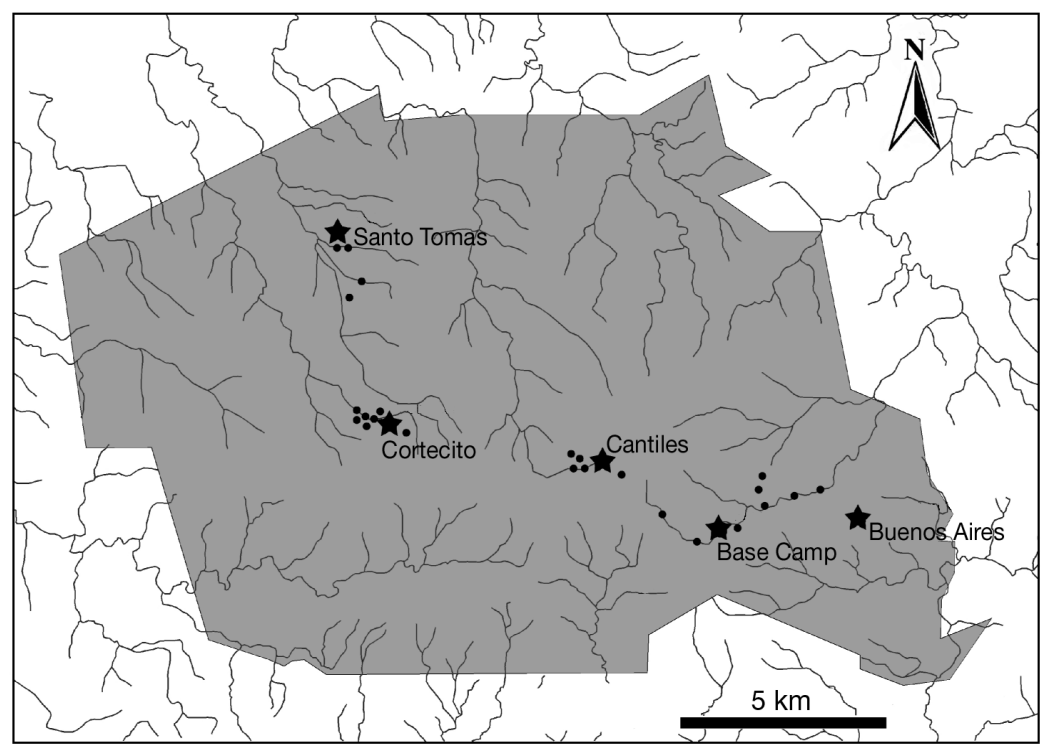

Fig. 1. Sites of sampling efforts and Batrachochytrium dendrobatidis detection within Cusuco National Park, Honduras. Base Camp situated at $15.50^{\circ} \mathrm{N}$, $88.2^{\circ} \mathrm{W}$. Shaded area: Cusuco National Park; lines: streams. Stars: regions of concentrated survey efforts. Dots: localities where infected amphibians were detected 
was used as a preservative since the high relative humidity prevented air drying. Each amphibian was sampled using an individually wrapped sterile swab with a fine-tipped rayon bud (Medical Wire \& Equipment). The ventral surfaces of the legs, feet, and drink patches of adult frogs and salamanders were swabbed 5 times each, applying moderate friction. For tadpoles, the swab was inserted into the oral cavity and twirled several times. Swab buds were snapped off and stored in $2 \mathrm{ml}$ microcentrifuge tubes containing $1 \mathrm{ml}$ of preservative. Samples were submitted to Pisces Molecular for molecular analysis to detect the presence of $B$. dendrobatidis. Swabs were run through PCR amplification using an assay developed by Annis et al. (2004) and modified for greater specificity and sensitivity at Pisces. In addition to PCR analysis, a small series of tadpoles was prepared for histological examination to visually confirm infection. Throughout the fieldwork, careful notes were recorded relative to possible symptoms of amphibian chytridiomycosis, including larval oral defects, physical and behavioral anomalies, and irregular or excessive skin sloughing.

\section{RESULTS}

PCR results confirmed the widespread presence of Batrachochytrium dendrobatidis in Cusuco National Park (Fig. 1). Of 257 amphibians sampled, $114(44.4 \%)$ tested positive for infection by $B$. dendrobatidis. All posi- tive results were confined to 5 of 16 species sampled: Craugastor rostralis, Duellmanohyla soralia, Plectrohyla dasypus, Ptychohyla hypomykter, and Lithobates maculata (Table 1). Susceptibility to infection had not previously been recorded in $C$. rostralis, $D$. soralia, and $P$. dasypus. Infection prevalence exhibited a general trend through the life stages, showing an increase in prevalence from larvae to subadult, but then sharply decreasing from subadult to adult (Table 2).

Lithobates maculata is the most aquatic of the 5 infected species, spending the majority of its time in direct contact with water throughout all life stages. Conversely, Craugastor rostralis is a terrestrial species in which larvae undergo direct metamorphosis on the forest floor and thus is the taxon least dependent upon aquatic environments. Duellmanohyla soralia, Plectrohyla dasypus, and Ptychohyla hypomykter all have aquatic larvae and semiarboreal adults that can be found in riparian zones amid moist vegetation.

Table 1. Amphibian species sampled for Batrachochytrium dendrobatidis infection in Cusuco National Park, Honduras. IUCN Red List category (CR: critically endangered, EN: endangered, NT: near threatened, LC: least concern, NL: not listed), larval natural history (A: aquatic, T: terrestrial direct development), and adult microhabitat (A: aquatic; Ar: aboreal; B: bromeliad; R: riparian; T: terrestrial)

\begin{tabular}{|c|c|c|c|c|c|}
\hline Species & No. sampled & Prevalence (\%) & IUCN cat. & Larvae & Microhabitat \\
\hline Bolitoglossa conanti & 2 & 0 & EN & $\mathrm{T}$ & $\mathrm{Ar}$ \\
\hline Bolitoglossa diaphora & 1 & 0 & $\mathrm{CR}$ & $\mathrm{T}$ & $\mathrm{Ar}$ \\
\hline Bromeliohyla bromeliacea & 4 & 0 & EN & A & $\mathrm{B}$ \\
\hline Bufo valliceps & 1 & 0 & $\mathrm{LC}$ & A & $\mathrm{T}$ \\
\hline Craugastor charadra & 4 & 0 & EN & $\mathrm{T}$ & $\mathrm{T}, \mathrm{R}$ \\
\hline Craugastor coffeus & 8 & 0 & $\mathrm{CR}$ & $\mathrm{T}$ & $\mathrm{T}$ \\
\hline Craugastor rostralis & 41 & 4.9 & NT & $\mathrm{T}$ & $\mathrm{T}$ \\
\hline Cryptotriton nasalis & 1 & 0 & EN & $\mathrm{T}$ & $\mathrm{Ar}$ \\
\hline Duellmanohyla soralia & 53 & 39.6 & $\mathrm{CR}$ & A & $\mathrm{R}, \mathrm{Ar}$ \\
\hline Eleutherodactylus laevissimus & 1 & 0 & EN & $\mathrm{T}$ & $\mathrm{T}, \mathrm{R}$ \\
\hline Hyalinobatrachium fleischmanni & 2 & 0 & LC & A & $\mathrm{Ar}, \mathrm{R}$ \\
\hline Lithobates maculata & 38 & 63.2 & LC & A & A \\
\hline Oedipina tomasi & 1 & 0 & NL & $\mathrm{T}$ & $\mathrm{T}$ \\
\hline Plectrohyla dasypus & 59 & 78.0 & $\mathrm{CR}$ & A & $\mathrm{Ar}, \mathrm{R}$ \\
\hline Plectrohyla exquisita & 1 & 0 & $\mathrm{CR}$ & A & Ar, R \\
\hline Ptychohyla hypomykter & 40 & 57.5 & $\mathrm{CR}$ & A & $\mathrm{Ar}, \mathrm{R}$ \\
\hline
\end{tabular}


One subadult Plectrohyla dasypus displayed clinical symptoms characteristic of amphibian chytridiomycosis. Upon encountering it, this individual appeared lifeless, lying upside-down and fully submerged in an area of calm water along the shallow edge of a river (Fig. 2). When removed from the water for swabbing, the amphibian unexpectedly convulsed, hands and feet tightly clenched, and appeared to gasp for air. Moments later the animal stiffened, legs fully extended, and expired in hand. PCR results revealed heavy Batrachochytrium dendrobatidis infection in this individual.

Histological examination confirmed the presence of Batrachochytrium dendrobatidis within the keratinizing tissues of all species examined: Duellmanohyla soralia, Lithobates maculata, Plectrohyla dasypus, and Ptychohyla hypomykter (Fig. 3). Two larval P. dasypus were examined; one exhibited oral defects in the form of eroded jaw sheaths and disrupted tooth rows, and one displayed outwardly healthy oral structures. Amphibian chytridiomycosis was detected in the individual with oral defects, whereas $B$. dendrobatidis was not detected in the latter.

Larval oral defects were noted to be a common occurrence while swabbing for Batrachochytrium dendrobatidis. The oral defects observed with a $10 \times$ hand lens were limited to Plectrohyla dasypus and Ptychohyla hypomykter and included abnormal jaw sheaths and tooth row formations. Tooth rows of affected individuals were completely missing, greatly reduced, or disrupted. Defects in jaw sheaths often manifested as a lack of keratinization and moderate to

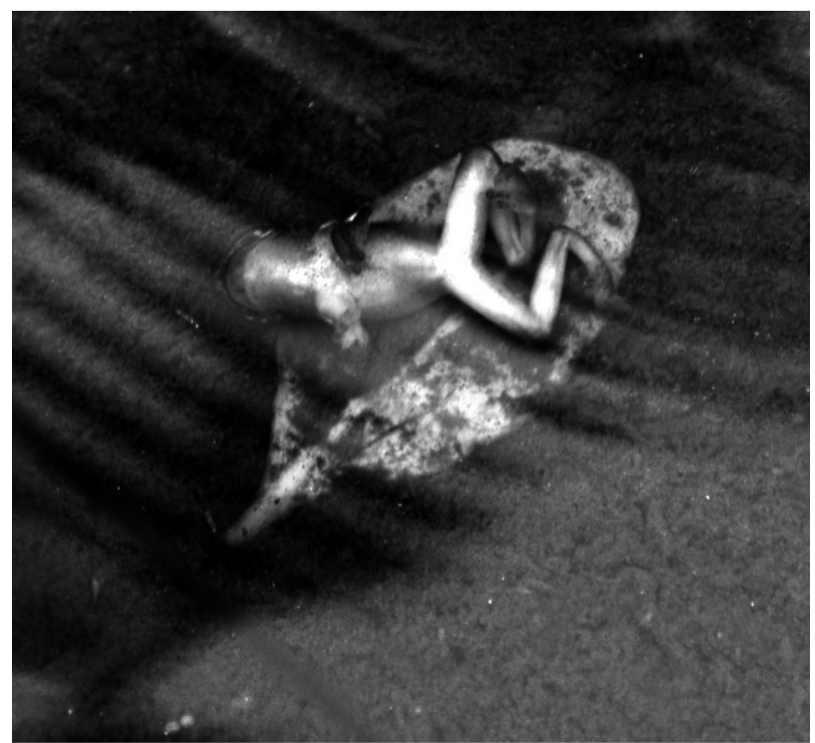

Fig. 2. Plectrohyla dasypus. Moribund subadult in Cusuco National Park, Honduras. PCR results confirmed a heavy infection load of Batrachochytrium dendrobatidis
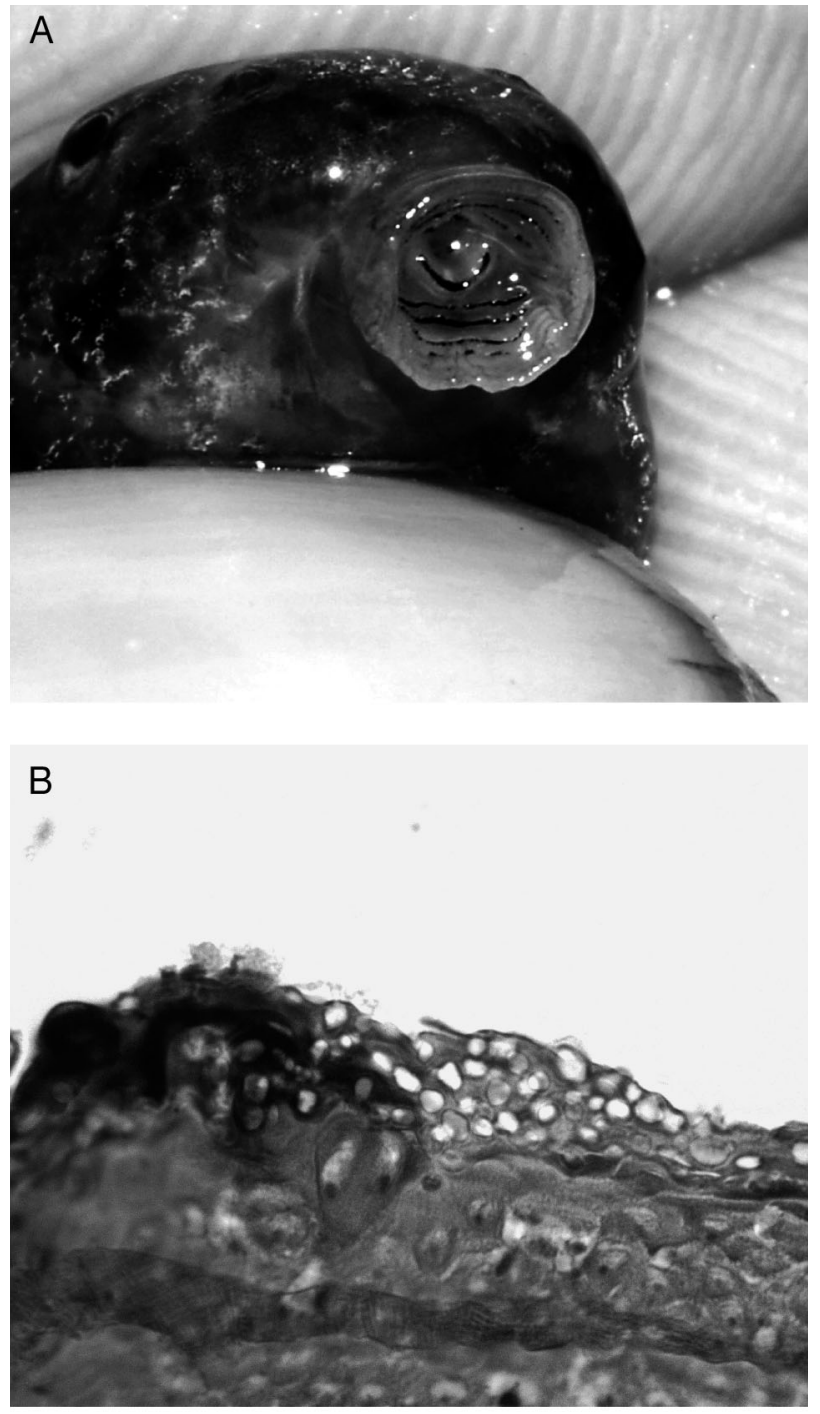

Fig. 3. Ptychohyla hypomykter. Larva infected with Batrachochytrium dendrobatidis. (A) Specimen with oral defects observed in situ. (B) Histological section of the same specimen, displaying cutaneous infection within the oral cavity. Viewed at $400 \times$ magnification

heavy erosion of cutting edges (Fig. 3A, Fig. 4). Instances of severe oral defects were also present, where a complete absence of all keratinized oral structures was observed. Tadpoles of P. dasypus and P. hypomykter that displayed oral defects were found throughout Cusuco National Park, often side by side with intraspecific larvae displaying superficially normal oral structures. Oral defects were not apparent among the 22 infected Lithobates maculata tadpoles examined, despite carrying heavy loads of $B$. dendrobatidis. Defects were also not recorded in Duellmanohyla soralia, but this could be attributed to the greater morphological complexity of this species' oral structures and the increased difficulty this poses in detecting such defects under 

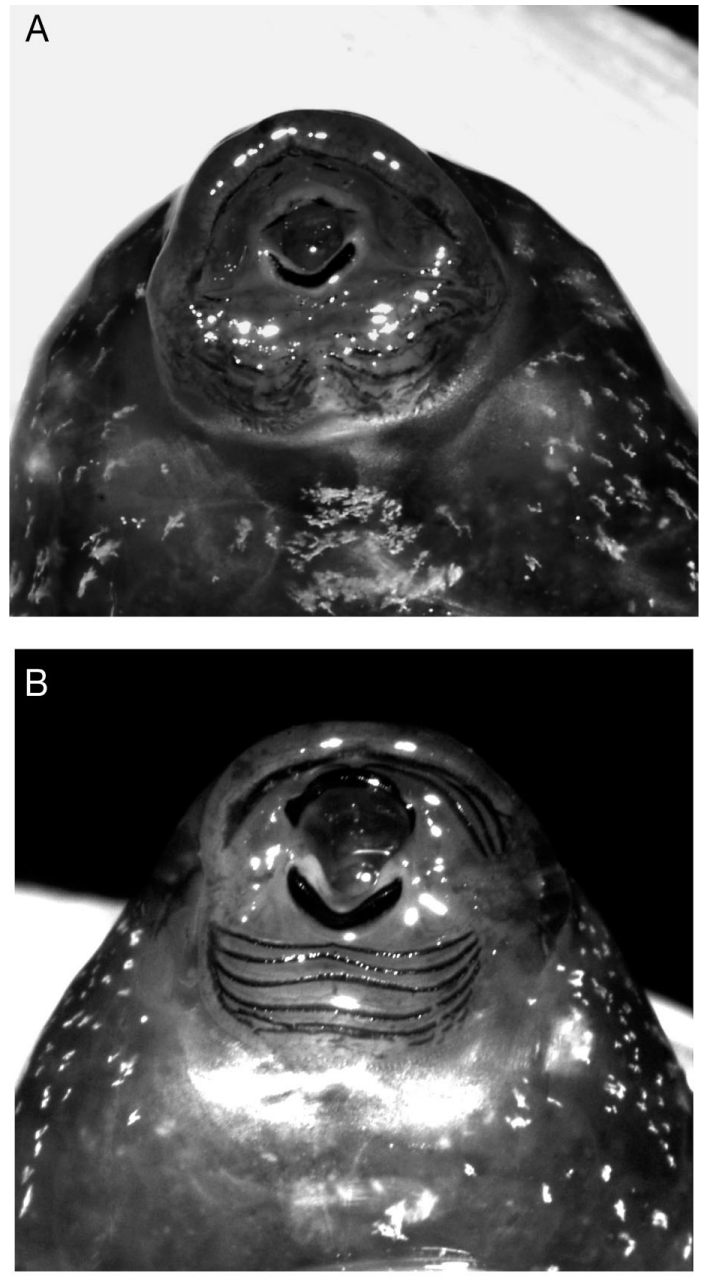

Fig. 4. Ptychohyla hypomykter. Larval oral defects observed in Cusuco National Park, Honduras. (A) Faint tooth rows, disrupted tooth rows, and erosion of jaw sheath cutting edges. (B) Normal tooth formation and keratinized jaw sheaths

suboptimal field conditions. At most study sites, tadpoles of D. soralia, P. dasypus, L. maculata, and P. hypomykter were sympatric.

\section{DISCUSSION}

Cusuco National Park is an area of extremely high herpetological diversity and is of great conservation importance. It is home to 6 amphibian species listed as critically endangered (CR) in the Red List of Threatened Species (IUCN 2007), 6 more listed as endangered (EN), and 1 species listed as extinct (EX). The results presented herein now confirm Batrachochytrium dendrobatidis infection in $50 \%$ of these critically endangered species (Table 1). Plectrohyla dasypus is of particular concern, as this species is endemic to Cusuco National Park, and an estimated $80 \%$ popu- lation decline has already been reported (Cruz et al. 2004a). Continuous habitat degradation coupled with the unpredictable dynamics of a poorly understood $B$. dendrobatidis epizootic may already be driving this species towards extinction.

Although this investigation did not detect Batrachochytrium dendrobatidis infection within the limited number of samples collected from Plectrohyla exquisita or Bolitoglossa diaphora, studies suggest that these critically endangered species may be highly vulnerable. A close relationship between phylogeny and infection response has been illustrated (Knapp \& Morgan 2006), suggesting that the sensitivity of $P$. exquisita to infection may be similar to that of the acute susceptibility exhibited by $P$. dasypus, the only other member of its genus within Cusuco National Park. Even more disquieting, during 14 wk of stream surveying conducted from 28 June to 8 August 2006 and 27 June to 21 August 2007, not a single P. exquisita tadpole nor metamorphosing froglet could be found among the hundreds of Duellmanohyla soralia, Lithobates maculata, P. dasypus, and Ptychohyla hypomykter larvae identified. In the past, these currently 'missing' life stages could be found within the same water bodies at similar times of the year; tadpoles were encountered during May and August and metamorphosing froglets during May, July, and August (McCranie \& Wilson 2002). For reasons yet unknown, it appears that the reproductive success of this species is experiencing an alarming decline.

Similar phylogenetic susceptibility inferences can be directed towards Bolitoglossa diaphora. A group of 6 B. dofleini imported into Belgium via the international pet trade appeared healthy upon arrival, but eventually succumbed to an unknown malady. Postmortem histological examinations revealed widespread Batrachochytrium dendrobatidis infections (Pasmans et al. 2004). Although the cause of death remains inconclusive, clinical symptoms consistent with that of amphibian chytridiomycosis were evident in the behavior of these animals prior to expiration. It is possible that the susceptibility of $B$. dofleini to developing the disease may have been exacerbated by excessive stress and consequential immunosuppression experienced during collection and international transport. Regardless, this instance may be indicative of the susceptibility of bolitoglossine salamanders, and specifically $B$. diaphora, to amphibian chytridiomycosis. It is important to note that although the majority of its habitat is still pristine, the population of $B$. diaphora in Cusuco National Park is reported to be experiencing a decline for unknown reasons (Cruz et al. 2004b).

Cusuco National Park is one of few sites in Honduras where an inexplicable amphibian population crash has been well documented (Cruz \& Wilson 2004). Craugas- 
tor milesi, a species endemic to Honduras, was historically abundant in Cusuco and Cerro Azul National Parks. During the mid-1980s, this species experienced a precipitous decline despite the pristine condition of both locales. After years of failed attempts to relocate C. milesi, the species was declared extinct. It is unknown what role, if any, Batrachochytrium dendrobatidis played in the disappearance of this streamside, direct-developing species, but neither habitat degradation nor resource exploitation alone can explain the sudden demise of this species from within both national parks.

Current data and former investigations suggest that Batrachochytrium dendrobatidis may have become established in Cusuco National Park as early as 1996. Morphological examination of a series of Plectrohyla dasypus and Ptychohyla hypomykter larvae collected from Cusuco National Park in 1996 found that oral defects were already a common occurrence in both species by this time (Wilson \& McCranie 2004b). In 2007, the presence of oral defects in $P$. dasypus and $P$. hypomykter larvae both showed high positive correlations with $B$. dendrobatidis infection (100 and $80 \%$, respectively). Numerous environmental and developmental factors are capable of producing oral deformities in larval amphibians, and it would be erroneous to blindly use this phenomenon to diagnose chytridiomycosis (Altig 2007). For example, Padgett-Flohr \& Goble (2007) found that for the 4 anuran species they tested, oral defects were not associated with $B$. dendrobatidis infection. Nonetheless, certain species such as those described herein do appear to show significant correlations between $B$. dendrobatidis infection and patterns of oral defects, again reiterating a phylogenetic link between $B$. dendrobatidis infection and pathological expression (Knapp \& Morgan 2006, Drake et al. 2007). Smith \& Weldon (2007) suggested that within a region of known $B$. dendrobatidis infection, the presence of larval oral defects can serve as a useful tool in identifying infected larvae. Although the existence of B. dendrobatidis was still unknown during the herpetological surveys of Cusuco National Park in 1996, the strong positive correlations observed in 2007 coupled with the morphological descriptions of historical specimens suggest that $B$. dendrobatidis infiltrated Honduras prior to 1996. According to the assessment of P. dasypus in the IUCN Red List of Threatened Species (Cruz et al. 2004a), this species has experienced '...a drastic population decline estimated to be more than $80 \%$ over the last ten years...' which, if indicative of a chytridiomycosis-induced decline, would additionally support this temporal context.

In summary, the amphibians of Cusuco National Park appear to be in great jeopardy. Although amphibian chytridiomycosis has now been confirmed within species reported to be experiencing population declines, additional investigations are necessary before assessing the extent to which such declines can be directly attributed to Batrachochytrium dendrobatidis. Nonetheless, significant changes in environmental conditions are likely to exacerbate and complicate the threat posed by the presence of $B$. dendrobatidis. Despite its 'national park' status, habitat degradation and agricultural practices continue to impact Cusuco National Park, altering microclimates and chemical environments inhabited by amphibians. Such changes may expose resident amphibians to unpredictable combinations of environmental stressors, affecting their health and further complicating the ways in which they respond to $B$. dendrobatidis infections. Variations in water chemistry and changes in air temperature may similarly affect the growth and activity of B. dendrobatidis (Berger et al. 2004, Piotrowski et al. 2004, Pounds et al. 2006). The interaction(s) between such factors present a multifaceted situation with the potential to catalyze changes in the rates at which amphibians become infected with $B$. dendrobatidis and/or manifest amphibian chytridiomycosis. These same dynamics may similarly cause stress-induced immunosuppression and interrupt the mechanisms of innate resistance displayed by some species. The production of antimicrobial skin peptides and the composition of cutaneous microbial fauna are key factors in the resistance displayed by some species (RollinsSmith et al. 2002, Woodhams et al. 2007a,b), but the resilience of these pathways is not well understood. Therefore, one should be cautious about formulating generalizations regarding $B$. dendrobatidis susceptibility based on phylogeny alone, as this may generate a false sense of security for species believed to be 'resistant' and unsusceptible to amphibian chytridiomycosis. Habitat protection within Cusuco National Park, as elsewhere, may have an overarching influence on the future survival of endangered amphibian communities due to the indirect influences upon wildlife disease epizootics. It is important that additional studies continue to monitor the effects of amphibian chytridiomycosis upon Honduran amphibian communities and that populations be managed responsibly in order to avoid future extinctions.

Acknowledgements. Financial support was provided by the National Geographic Society (Young Explorers Grant \#826707), Critical Ecosystem Partnership Fund (07-849), North of England Zoological Society-Chester Zoo, and Declining Amphibian Populations Task Force. Collection and export permits were granted by C. Cárcamo de Martínez of AFECODEHFOR, Tegucigalpa. J. R. McCranie and L. D. Wilson offered significant assistance with amphibian identification. Personnel of Operation Wallacea provided crucial logistical support while in the field, especially T. Coles, J. Nuñez-Miño, 
and A. Tozer. J. Wood (Pisces Molecular, LLC) processed the PCR samples. K. L. Richards-Hardlicka, R. McDiarmid, R. Altig, and countless others provided invaluable guidance and critiques without which this investigation would not have been possible. J.E.K. also expresses his gratitude to Dr. J. D. Lazell for the endless support and encouragement that he has provided over the past decade.

\section{LITERATURE CITED}

Altig R (2007) Comments on the descriptions and evaluations of tadpole mouthpart anomalies. Herpetol Conserv Biol $2: 1-4$

Annis SL, Dastoor FP, Ziel H, Daszak P, Longcore JE (2004) A DNA-based assay identifies Batrachochytrium dendrobatidis in amphibians. J Wildl Dis 40:420-428

Berger L, Speare R, Kent A (1999) Diagnosis of chytridiomycosis of amphibians by histological examination. Zoos Print J 15:184-190

Berger L, Speare R, Hines H, Marantelli G and others (2004) Effect of season and temperature on mortality in amphibians due to chytridiomycosis. Aust Vet J 82:31-36

Cruz G, Wilson LD (2004) Craugastor milesi. In: IUCN (ed) 2007 IUCN Red List of Threatened Species. Available at: www.iucnredlist.org

Cruz G, Wilson LD, Casteñeda F (2004a) Plectrohyla dasypus. In: IUCN (ed) 2007 IUCN Red List of Threatened Species. Available at: www.iucnredlist.org

Cruz G, Wilson LD, McCranie R (2004b) Bolitoglossa diaphora. In: IUCN (ed) 2007 IUCN Red List of Threatened Species. Available at: www.iucnredlist.org

Di Rosa I, Simoncelli F, Fagotti A, Pascolini R (2007) Ecology: the proximate cause of frog declines? Nature 447:E4-E5

Drake DL, Altig R, Grace JB, Walls SC (2007) Occurrence of oral defects in larval anurans. Copeia 2007:449-458

Felger J, Enssle J, Mendez D, Speare R (2007) Chytridiomycosis in El Salvador. Salamandra 43:122-127

Field R, Long P (2007) Cusuco National Park, Honduras: ecology of a Meso-American cloud forest. Operation Wallacea 2007 Field Report. University of Nottingham

Hyatt AD, Boyle DG, Olsen V, Boyle DB and others (2007) Diagnostic assays and sampling protocols for the detection of Batrachochytrium dendrobatidis. Dis Aquat Org 73: 175-192

IUCN (2007) 2007 IUCN Red List of Threatened Species. Available at: www.iucnredlist.org

Knapp RA, Morgan JAT (2006) Tadpole mouthpart depigmentation as an accurate indicator of chytridiomycosis, an emerging disease of amphibians. Copeia 2006:188-197

Lips KR (1999) Mass mortality and population declines of anurans at an upland site in Western Panama. Conserv Biol 13:117-125

Lips KR, Green DE, Papendick R (2003) Chytridiomycosis in wild frogs from southern Costa Rica. J Herpetol 37: 215-218

Lips KR, Mendelson JR III, Muñoz-Alonso A, Canseco-Marquez L, Mulcahy DG (2004) Direct evidence of declines in amphibian populations in montane southern Mexico. Biol Conserv 119:555-564

Longcore JE, Pessier AP, Nichols DK (1999) Batrachochytrium dendrobatidis gen. et sp. nov., a chytrid pathogenic to amphibians. Mycologia 91:219-227

Editorial responsibility: Alex Hyatt,

Geelong, Victoria, Australia
McCranie JR, Wilson LD (2002) The amphibians of Honduras. Society for the Study of Amphibians and Reptiles, Ithaca, NY

Mendelson JR, Brodie ED Jr, Malone JM, Acevedo ME, Baker MA, Smatresk NJ, Campbell JA (2004) Investigation of factors associated with the catastrophic decline of a cloudforest frog fauna in Guatemala. Rev Biol Trop 52:991-1000

Padgett-Flohr GE, Goble ME (2007) Evaluation of tadpole mouthpart depigmentation as a diagnostic test for infection by Batrachochytrium dendrobatidis for four California anurans. J Wildl Dis 43:690-699

Pasmans F, Zwart P, Hyatt AD (2004) Chytridiomycosis in the Central American bolitoglossine salamander (Bolitoglossa dofleini). Vet Rec 154:153

Piotrowski JS, Annis SL, Longcore JF (2004) Physiology of Batrachochytrium dendrobatidis, a chytrid pathogen of amphibians. Mycologia 96:9-15

Pounds JA, Bustamante MR, Coloma LA, Consuegra JA and others (2006) Widespread amphibian extinctions from epidemic disease driven by global warming. Nature 439:161-167

Puschendorf R, Castañeda F, McCranie JR (2006) Chytridiomycosis in wild frogs from Pico Bonito National Park, Honduras. EcoHealth 3:178-181

> Rollins-Smith LA, Carey C, Longcore J, Doersam JK, Boutte A, Bruzgal JE, Conlon JM (2002) Activity of antimicrobial skin peptides from ranid frogs against Batrachochytrium dendrobatidis, the chytrid fungus associated with global amphibian declines. Dev Comp Immunol 26:471-479

Schloegel LM, Hero JM, Berger L, Speare R, McDonald K, Daszak P (2006) The decline of the sharp-snouted day frog (Taudactylus acutirostris): the first documented case of extinction by infection in a free-ranging wildlife species? EcoHealth 3:35-40

Skerratt LF, Berger L, Speare R, Cashins S and others (2007) Spread of chytridiomycosis has caused the rapid global decline and extinction of frogs. EcoHealth 4:125-134

> Smith KG, Weldon C (2007) A conceptual framework for detecting oral chytridiomycosis in tadpoles. Copeia 2007:1024-1028

Stuart SN, Chanson JS, Cox NA, Young BE, Rodrigues ASL, Fischman DL, Waller RW (2004) Status and trends of amphibian declines and extinctions worldwide. Science 306:1783-1786

> Weldon C, Du Preez LH, Hyatt AD, Muller R, Speare R (2004) Origin of the amphibian chytrid fungus. Emerg Infect Dis 10:2100-2105

Wilson, LD, McCranie JR (2004a) The conservation status of the herpetofauna of Honduras. Amphib Reptile Conserv 3:6-33

Wilson LD, McCranie JR (2004b) The herpetofauna of Parque Nacional El Cusuco, Honduras (Reptilia, Amphibia). Herpetol Bull 87:13-24

Woodhams DC, Ardipradja K, Alford RA, Marantelli G, Reinert LK, Rollins-Smith LA (2007a) Resistance to chytridiomycosis varies among amphibian species and is correlated with skin peptide defenses. Anim Conserv 10: 409-417

Woodhams DC, Vredenburg VT, Simon MA, Billheimer D and others $(2007 \mathrm{~b})$ Symbiotic bacteria contribute to innate immune defenses of the threatened mountain yellowlegged frog, Lithobates muscosa. Biol Conserv 138: 390-398

Submitted: May 13, 2008; Accepted: March 2, 2009

Proofs received from author(s): April 24, 2009 